\title{
Kamu Yönetiminde Beşeri Sermaye ve Eleştirel Düşünme Eğilimi İlişkisi: Kamu Personeli'ne Yönelik Bir Araştırma \\ (Relation of Human Capital and Critical Thinking Tendency in Public Administration: A Research on Civil Cervant)
}

\author{
Şerafettin ERTEN ID a İbrahim TÜRKMEN (iD $b$ \\ a Uşak Üniversitesi, Sağlık Yüksekokulu, Uşak, Türkiye. serafettin.erten@usak.edu.tr \\ b Uşak Üniversitesi, Sağlık Hizmetleri Meslek Yüksekokulu, Uşak, Türkiye. ibrahim.turkmen@usak.edu.tr
}

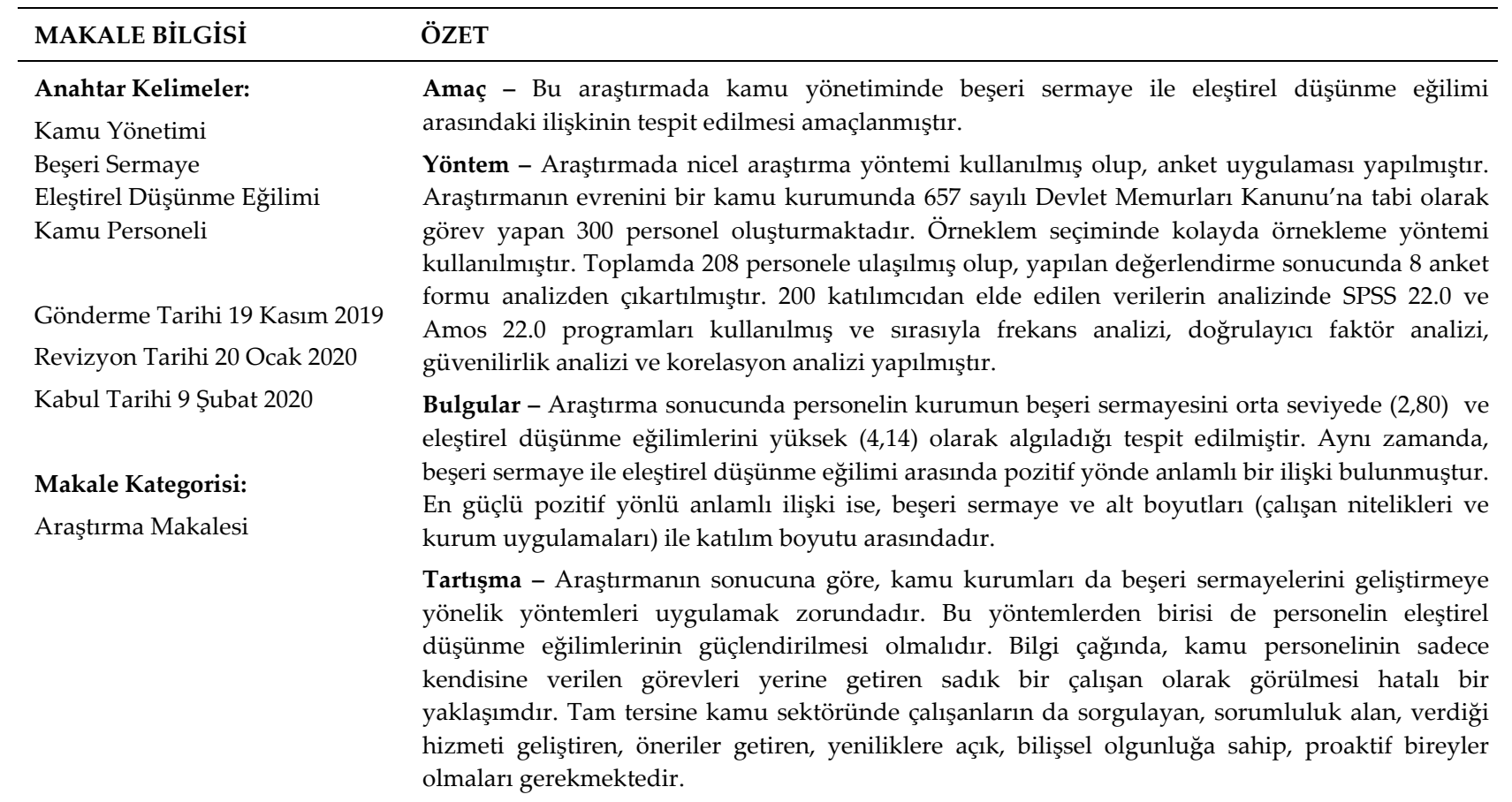

\begin{tabular}{l}
\hline ARTICLE INFO \\
\hline Keywords: \\
Public Administration \\
Human Capital \\
Critical Thinking Tendency \\
Civil Servant
\end{tabular}

\section{ABSTRACT}

Purpose - In this study, it is aimed to determine the relationship between human capital and critical thinking tendency in public administration.

Design/Methodology/Approach - Quantitative research method was used in the research and a questionnaire was applied. The population of the study consists of 300 personnel working in a public institution subject to the Civil Servants Law No. 657. Sample selection method was used in sampling. A total of 208 personnel were reached and as a result of the evaluation, 8 questionnaires were excluded from the analysis. SPSS 22.0 and Amos 22.0 programs were used to analyze the

Received 19 Novebmer 2019

Revised 20 January 2020

Accepted 9 February 2020

Article Classification:

Research Article data obtained from 200 participants and frequency analysis, confirmatory factor analysis, reliability analysis and correlation analysis were performed respectively.

Findins -As a result of the research, it was determined that the personnel perceived the human capital of the institution as medium (2.80), and the tendency of critical thinking to be high (4.14). At the same time, a positive meaningful relationship was found between human capital and critical thinking tendency. The strongest positive relationship is between human capital and its sub-dimensions (employee qualifications and institution practices) and participation dimension.

Discussion - According to the resaults of the research, public institutions have to apply methods to develop their human capital. One of these methods should be strengthening the critical thinking tendencies of the personnel. In the information age, it is a wrong approach to see public personnel as a loyal employee performing only the tasks assigned to him. On the contrary, employees in the public sector should also be individuals who are questioners, take responsibility, develop their services, make suggestions, open to innovation, have cognitive maturity and are proactive. 


\section{GíRiş}

İnsanoğlu endüstri çağını geride bırakıp, yeni bir çağa adım atmıştır. Bu yeniçağa bilgi çağı, toplumuna bilgi toplumu ve ekonomisine de bilgi ekonomisi adı verilmektedir. Başta üretim faktörleri ve biçimi olmak üzere, sosyal, kültürel, siyasal vb. yapılar ile insani süreçler ve bunların etkileşiminden oluşan hemen her şey hızla değişmektedir. Bu değişim süreci içerisinde gelişimin ve ilerlemenin ana kaynağı bilgiyi üretme, işleme ve bunu ürün veya hizmete dönüştürmektir (Castells, 2013: 21). Bilgi, başta ekonomi olmak üzere hayatın her alanına hâkimdir. Endüstri çağının fabrika, makine, hammadde gibi kilit kavramları yerini uzmanlık, yenilik, üretkenlik, verimlilik, kalite, hız gibi maddi olmayan kavramlara bırakmıştır (Akyüz, 2011: 31). Artık emek, sermaye, doğal kaynaklar ve girişimcinin yanında bilgi, beşinci üretim faktörü olarak sayılmaktadır (Arıkboğa, 2003: 70). Yeni yapıda üretimin temel belirleyici faktörü insanın kendisi, yani bilgidir. Bilgi üretilen, yapılan, satılan, satın alınan her şeyin temel bileşenidir. Bu nedenle bilginin yönetilmesi, bir başka ifadeyle entelektüel sermayenin bulunması, geliştirilmesi, elde tutulması ve ürüne dönüştürülmesi bireylerin, örgütlerin ve ülkelerin en önemli görevi haline gelmiştir (Stewart, 1997: 13).

Entelektüel sermaye en genel ifadeyle " bir kuruluşun faaliyetlerini sürdürmesini sağlayan maddi olmayan unsurların tamamıdır (Brooking, 1996: 12)." Bu sermaye türünün beşeri sermaye, yapısal sermaye, müşteri sermayesi, ilişki sermayesi, süreç sermayesi gibi çeşitli unsurlardan oluştuğu kabul edilmektedir. Bunların içerisinde ise beşeri sermayeye daha fazla vurgu yapıldığı görülmektedir (Edvinsson, 1997; Stewart, 1997; Bontis, 1998; Petty ve Guthrie, 2000). Beşeri sermaye "bireyin sahip olduğu nitelikleri, bilimsel ve teknik bilgisi, becerileri, hareketliliği ve deneyimi" olarak ifade edilmektedir (OECD, 1999). Beşeri sermayeye bu kadar önem atfedilmesinin ise birkaç nedeni bulunmaktadır. Öncelikle yeni yapıda fiziksel gücün yerini, beyin gücüne bıraktığı görülmektedir. İkincisi maddi olmayan varlıkların artan önemi ile birlikte yüksek nitelikli yani bilgili, tecrübeli, çok yönlü beceri sahibi, yenilikçi ve yaratıcı bireylere olan ihtiyaç ve talep de artmıştır. Son olarak ve belkide en önemlisi bilginin inovasyona, ürüne veya hizmete dönüşmesi için çeşitli aşamalardan geçmesi gerekmektedir ve bu sürecin en başta gelen aktörü insandır (Stewart, 1997; Özsağır, 2016; Drucker, 2017).

Bilgi toplumunun insan kaynağını oluşturan bu bireyler ihtiyaçları belirlemede, problemleri çözmede, kararları almada ve çalıştıkları alanlarda işbirliğine gitmede uzmanlaşmıştır (Davenport, 2006: 12). En başta gelen özellikleri ise kendilerini sürekli geliştirmeleri ve açık, yapıcı, yaratıcı, yansıtıcı ve eleştirel düşünme becerisine sahip olmalarıdır (Özkan, 2009: 121). Temel bir özellik olarak eleştirel düşünme bireylere akılcı, mantıklı, sistematik ve sorgulayıcı bir yöntemle isabetli kararlar verebilme, problemleri daha etkin bir şekilde çözebilme ve farklı ve karmaşık durumlara daha geniş bir perspektifle bakabilme olanağ1 sağlamaktadır. Çünkü eleştirel düşünme, öncelikle konu ile ilişkili bilginin özümsenmesini ve ardından bu bilginin en isabetli şekilde kullanılmasını ifade etmektedir (Segler, 2015: 7).

Kamu sektörü ya da özel sektör ayırt etmeksizin günümüz örgütleri için beşeri sermaye en önemli rekabet ve avantaj kaynağı haline gelmiştir. Dolayısıyla örgütlerde beşeri sermayenin niteliği stratejik bir öneme sahiptir. Beşeri sermayenin bilgiyi nasıl elde ettiği, dönüştürdüğü ve kullandığı örgütlerin performansını doğrudan etkilemektedir. Eleştirel düşünme de bu süreçte kullanılabilecek başlıca araçlardan birisidir. Bu bağlamda araştırmanın amacı da kamu personelinin beşeri sermaye düzeyi ile eleştirel düşünme eğilimi arasındaki ilişkiyi ortaya koymaktır.

\section{KAVRAMSAL ÇERÇEVE}

\subsection{Beşeri Sermaye}

Bilgi ekonomisi örgütlerde maddi olmayan varlıkları, maddi varlıklardan daha önemli hale getirmiştir. Bilginin her türlü formu örgütler için performansın ana kaynağı olarak kabul edilmektedir. Kurumların, kuruluşların ve bireylerin değeri, kendi bilgileri ve entelektüel sermayeleriyle doğrudan ilgilidir (Bounfour ve Edvinsson, 2005). Bu nedenle bilgi çağı kuruluşları her zamankinden daha fazla beşeri sermayeye dayanmak durumundadır (Stewart, 1997: 111).

Literatür incelendiğinde beşeri sermayenin çok çeşitli ve birbirine benzer şekilde tanımlandığ1 görülmektedir. Dolayısıyla bu tanımlardan yola çıkarak kavramı, "bir örgütte bireye ait olan bilgi, beceri, yetenek, deneyim, değerler, fiziksel ve duygusal özellikler ile coşku ve enerjinin toplamı" olarak tanımlamak mümkündür (Becker, 1993; Weatherly, 2003; Agndal ve Nilsson, 2006; Roos, 2008). Beşeri sermaye de tıpk1 
entelektüel sermaye gibi bir takım unsurlardan oluşmaktadır. Bu unsurlar uzmanlık bilgisi, eğitim, mesleki nitelik, işle ilgili yeterlilikler, proaktif ve reaktif yetenekler, girişimci ruh, yenilikçilik ve değişime açı olmak olarak sayılmaktadır (Petty ve Guthrie, 2000: 166).

Beşeri sermayeye yapılan yatırım, karşılığında katma değere dönüşebilen bilgi ve kişisel özellikleri ortaya çıkarmaktadır. Bu nedenle beşeri sermayenin özellikle dikkate alınması gereken bir takım kritik nitelikleri olduğu kabul edilmektedir. Literatürde bu nitelikler aşağıdaki şekilde sayılmaktadır (Schultz, 1993; Bassi ve Van Buren, 1999; Roos, 2008; Farah ve Abouzeid, 2017) :

- Fiziksel sermayeden farklı olarak beşeri sermaye, sahip olan kişiden ayrılamaz, ondan alınamaz ve ona el konulamaz.

- Beşeri sermaye modern şirketlerin satın alamayacağı ya da satamayacağı tek tür sermaye olması nedeniyle diğer sermaye türlerinden ayrılır.

- Beşeri sermayeye sadece, insana yatırım yapılarak sahip olunabilir. Bu yatırımların yapılmasında önemli özel ve kamusal tercihler rol oynar.

- Beşeri sermaye doğuştan gelen ve sonradan kazanılan yetenekler toplamıdır. Yani bireyin sahip olduğu özelliklerin bir kısmı genetikken, önemli bir bölümü de sonradan elde edilir. Özellikle gelişmiş ülkeler incelendiğinde buradaki beşeri sermayenin yeteneklerinin büyük kısmının sonradan elde edildiği görülmektedir.

- Beşeri sermaye elle tutulabilir bir sermaye türü değildir. Ancak etkileri açık ve net bir şekilde gözlemlenebilir. Bu etkiler içsel ve dişsal olabilir.

Bilgi toplumu ve ekonomisinde beşeri sermayenin hem mikro düzeyde örgütler, hem de makro düzeyde ülkeler açısından vazgeçilmez bir unsur olduğu kabul edilmektedir. Bu bağlamda beşeri sermayenin örgütler ve ülkeler için önemi ve yaptığ katkı ise şu şekilde özetlenebilir (Stewart, 1997; Carkhuff, 2000; Oliver, 2001; Matovac vd., 2010; Sarnovics, 2010; Yeh-Yun Lin ve Edvinsson, 2011; Farah ve Abouzeid, 2017):

- Beşeri sermaye bilginin temel kaynağıdır.

- Üretkenliğin birinci ve asli unsuru beşeri sermayedir.

- Beşeri sermaye inovasyon ve teknolojinin yaratıcısıdır.

- Verimliliğin ve kazancın yolu nitelikli beşeri sermayeye sahip olmaktan geçmektedir.

- Örgütler için stratejik yenilenme kaynağıdır.

- Bilgi toplumu ve ekonomisinde rekabet gücünün belirleyicisidir.

- Yüksek katma değeri yaratan beşeri sermayedir.

- Nitelikli beşeri sermaye büyümenin, zenginliğin ve refahın kaynağıdır.

- Beşeri sermaye ilerlemenin ve gelişmenin kaynağıdır.

Bilgi çağında örgütlerin varlığını sürdürmesi, sürekli olarak yeni ve daha verimli cevaplar üretmelerine bağlıdır. Bu nedenle "üretken düşünce" temel gereksinim halini almıştır. Üretken düşünme, bir yanıt üretme ve/veya daha iyiyi düşünme sürecidir. Bunun anlamı, bireylerin her koşulda ve şartta iş yapmanın yeni ve daha verimli yollarını üretebilmesidir (Carkhuff, 2000). Başarılı örgütler ve gelişmiş ülkeler incelendiğinde beşeri sermayelerini güçlendirmenin çeşitli yollarını aradıkları ve geliştirdikleri yöntemleri uyguladıkları görülmektedir. Bu bağlamda kullanılabilecek yöntemlerden birisi de eleştirel düşünmedir.

\subsection{Eleştirel Düşünme}

Düşünme bir yargılama ve karar verme gücüdür. Bu güç ayrıca insanı diğer canlılardan ayıran ve dış dünyaya hükmetmesini sağlayan temel özelliğidir. Bu özellik sayesinde insan doğruyu ve yanlışı ayırt etmekte, gerçekliğe ulaşmaktadır (Guitton, 2011: 43). Düşünme bilinçli bir zihinsel süreçtir ve sonuçta ortaya bilgi veya eylem ortaya çımaktadır. Düşünmenin yansıtıcı, yaratıcı ve eleştirel olmak üzere üç geniş kategorisi bulunmaktadır. Eleştirel düşünme temelde verilerin test edildiği ve hangilerinin değerli ya da değersiz olduğuna karar verilen bir süreçtir (Ruggiero, 2017: 52). Günümüz dünyasında bireylerin eleştirel düşünme yeteneğine sahip olmaları daha önemli hale gelmiştir. Çünkü bireyler bilgiyi çok çeşitli ve farklı kaynaklardan elde etmektedir. Böyle bir ortamda karar vermek, problemleri çözmek ve toplumsal söylemde yer almak için bu bilginin güvenilir ve yararlı olup olmadığının eleştirel olarak sorgulanması gerekmektedir (Tarchi ve Mason, 2019). 
Zaman zaman kritik düşünme olarak da kavramlaştırılan eleştirel düşünme farklı şekillerde tanımlanmıştır. Scriven ve Paul (1987)'e göre eleştirel düşünme “ çeşitli yöntemlerle toplanan veya oluşturulan bilgileri etkin ve ustaca kavramsallaştırmanın, analiz etmenin, sentezlemenin ve/veya değerlendirmenin entelektüel olarak disiplinli bir işlemidir." Bu işlem açıklık, doğruluk, kesinlik, tutarlılık, alaka düzeyi, sağlam kanıt, iyi nedenler, derinlik, genişlik ve tarafsızlık gibi evrensel entelektüel değerlere dayanmaktadır. Lipman (1988: 38) eleştirel düşünmenin, "iyi ve doğru karar vermeyi kolaylaştıran yetenek ve sorumluluk gerektiren düşünme" olduğunu ifade etmiştir. Çünkü ona göre eleştirel düşünme ölçütlere dayanan, kendini düzeltici ve bağlama duyarlı bir etkinliktir. Ennis (2018: 166)'e göre eleştirel düşünme "neye inanacağına veya ne yapacağına karar vermeye odaklanan rasyonel bir yansıtıcı düşünmedir." Johnson ve Hamby (2015: 424)'ye göre ise "sorunları çözme, kanıtları analiz etme, çeşitli tarafların/durumların artılarını ve eksilerini görebilme, güçlü ve zayıf yönleri ağırlıklandırma ve gerekçeli bir yargıya varma yeteneğidir."

Eleştirel düşünmenin birbirini takip eden bir takım eylemlerden oluştuğu kabul edilmektedir. Eleştirel düşünmenin bileşenleri olarak ifade edilen bu eylemler literatürde çeşitli şekillerde sayılmıştır. Bir görüşe göre eleştirel düşünme süreci bir problemi analiz etme, verileri toplama, bunları değerlendirme, yorumlama ve bir karar verme eylemlerinden oluşmaktadır (Facione, 1990; Ruggiero, 2017; Zulmaulida vd., 2018). Diğer bir görüşe göre ise bu bileşenler çıkarım yapma, varsayımları belirleme, mantıksal akıl yürütme, kanıtları yorumlama, karar verme ve öz düzenlemedir (Possin, 2014; Martincova ve Lukesova, 2015). Bununla birlikte hangi görüş dikkate alınırsa alınsın temelde eleştirel düşünme, bireyin bir dizi bilgiyi ve inancı üretme ve işleme becerisi ile bu beceriyi kendi davranışlarında rehber olarak kullanma eyleminden oluşmaktadır (Weissberg, 2013: 318).

Düşünme eylemi her bireyde görülen ve süreklilik arz eden bir durumdur. Ancak farklı bir boyut olarak, eleştirel düşünme yeteneğine sahip olanların bir takım ortak özelliklerinin bulunduğu ileri sürülmektedir. Eleştirel düşünme yeteneği ve alışkanlığına sahip olanlar; hayata dair her konuda merakll, her şeyi anlamaya gayret eden, bilgili olma ve öyle kalma endişesi duyan, kendilerine karşı dürüst, bilmediklerini kabul eden, zor ve karmaşık durumlarda sabırlı ve bu tür konularla uğraşmayı seven, kanıta ve mantıklı akıl yürütmeye dayalı olarak karar veren, farklı fikirlere saygı duyan, önyargılara ve kalıp yargılara karşı ihtiyatll, eylemden önce düşünmeyi alışkanlık haline getiren, soru sorma ve sorgulama yeteneğine sahip ve alternatifleri sürekli göz önünde bulundurarak değişime açık kişilerdir (Facione, 1990; Ruggiero, 2017).

Eleştirel düşünme yeteneği ve alışkanlığı bireylere çok sayıda avantaj sağlamaktadır. Eleştirel düşünme bağımsız düşünme anlamına gelmektedir. Bir sorun ve konu hakkında bireyin fikir oluşturmasının yolu eleştirel düşünmedir (Segler, 2015: 8). Doğru kararları verebilmek eleştirel düşünmenin en tipik özelliği ve temel çıktısıdır (Lipman, 1988: 39). Eleştirel düşünme özellikle kritik kararları almada ve sorunları çözmede başvurulabilecek en önemli araçtır. Eleştirel düşünebilenler mantıklı, bilinçli ve planlı bir tercih seviyesine sahip oldukları için alınan kararlar ve sorunlara yönelik çözümler daha isabetli olmaktadır (Paul ve Elder, 2016). Eleştirel düşünme önemli bir sorgulama aracıdır (Facione, 1990: 3). Yenilikçilik ve keşif eleştirel düşünmenin önemli çıtılarındandır (Ruggiero, 2017: 57). Eleştirel düşünme bireyin entelektüel yeteneklerini geliştirerek, hedeflere daha kolay ulaşmasına yardımcı olur (Trevors, 2011: 1). Bireylere kavrama yeteneği kazandırır. Toplumdaki kimlik, sosyal roller, ideoloji gibi çok sayıda yapı ile ilişkilerinde onlara anlam yaratma olanağı sağlar. Bireylerin düşünce, etkinlik, ifade ve ilişki arasında anlamlı bağlantılar kurmalarına katkı sağlar(Alston, 2001: 38).

Bilgi çağı ve bilgi toplumu tarihi süreç içerisinde daha önce görülmemiş bir karmaşıklık düzeyine sahiptir. Temel meta olarak kabul edilen bilgiden, insanlar arasındaki ilişkilere ve sosyal yapılara kadar her şey hizla değişmekte ve eskimektedir. Dolayısıyla insanoğlu her geçen gün daha fazla sorunla karşılaşmakta ve daha yeni çözümlere ihtiyaç duymaktadır. Bu nedenle sağlıkl, üretken, şüphecilik konusunda eğitilmiş, aktif olarak veri ve kaynakları ilişkilendirip, değerlendirebilen, bağımsız düşünebilen ve elde ettikleri sonuçları destekleyecek sağlam dayanaklar oluşturabilen bireylere daha fazla ihtiyaç duyulmaktadır (Microsoft, 2014). $\mathrm{Bu}$ bağlamda eleştirel düşünme her düzeyde, birbirine bağlı sorunları netleştirmek, doğru ve ulaşılabilir hedefleri belirlemek, bilgi kaynaklarını değerlendirmek ve karmaşık sorunlara en iyi çözümleri üretmek için kullanılabilecek önemli bir araç olarak görülmektedir (Trevors, 2011: 1). 


\subsection{Beşeri Sermaye ve Eleştirel Düşünmenin Kamu Yönetiminde Yeri ve Önemi}

Neo-klasik örgüt kuramlarından bu tarafa insan faktörü örgütlerin önemli bir parçası haline gelmiştir. Bilgi ekonomisiyle birlikte özellikle maddi olmayan varlıklara yapılan vurgu, insana atfedilen değeri daha da artırmıştır. Bu gün beşeri sermaye özel teşebbüs kuruluşları için olduğu kadar, kamu sektörünün ve milletlerin üretkenliği ve rekabetçiliği için de vazgeçilmez bir kaynaktır (Bounfour ve Edvinsson, 2005). Doğal olarak gerek örgütler, gerek ülkeler için kaliteli beşeri sermayeyi bulmak ve korumak başlıca amaçlardan ve zorluklardan birisi olmuştur (Oliver, 2001: 7).

Kamu kuruluşları özel sektörden farklı olarak kamu yararını amaçlamaktadır. Faaliyetleri sonucunda da kamu hizmetini üretmektedir. Her iki unsurun yerine getirilmesinde kullanılan araç ise kamu personelidir. Dolayısıyla kamu kurumlarının hem amacı, hem kullandığı araçlar, hem de üretilen çıktı genel itibariyle maddi olmayan varlıklardan oluşmaktadır. (Cinca vd., 2003: 250). Kamu kurumlarının beşeri sermayesini oluşturan kamu personelinin bilgi, yetenek, beceri ve üretme kapasitesi ise kurumun hedef ve amaçlarına ulaşmasında en önemli rolü oynamaktadır (Campos vd., 2006: 222).

Bilgi çağı ile birlikte yaşanan hızlı değişim kamu yönetimi alanında etkilerini göstermiş ve göstermeye devam etmektedir. Kamu yararı, kamu hizmeti, kamu personeli, vatandaş gibi bu alana özgü temel kavramlar yeniden tanımlanmaya başlanmıştır. Değişimin hızı nedeniyle sıklıkla stratejiler, hedefler ve amaçlar yenilenmektedir. Planlama, örgütleme, yöneltme, kontrol ve koordinasyon gibi klasik yönetim fonksiyonlarını yerine getirirken artık daha hızlı ve istikrarlı kararlar verilmesi zorunlu hale gelmiştir (Daniello ve Laubsch, 2008: xii).

Kamu politikalarının geliştirildiği alan daha karmaşık, zorlu ve belirsiz bir yapıya bürünmüştür. Vatandaşların beklentileri değişmiş, bireysel ihtiyaçlara uyarlanmış hizmet talepleri artmıştır. Benzeri görülmemiş değişim ve bilgi akışı bir taraftan devletlerin yeni yetkinlikler geliştirme ihtiyacını doğururken, diğer taraftan da kamu personelinin daha kapsaml, daha uyumlu, daha esnek olmasını; aynı konu ya da sorunlar için birçok senaryoyu değerlendirebilmesini ve daha önce uygulanmamış çözümler üretebilmesini gerektirmektedir. Eleştirel düşünmeye olan ihtiyaç da bu noktada ortaya çıkmaktadır. Çünkü eleştirel düşünebilen insanlar standart dışı çözümler üretebilmekte, inovasyonu yaptıkları işin bir parçası haline getirebilmektedir. Dolayısıyla kamu personelinin görevlerini başarıyla yerine getirebilmesi için eleştirel düşünme yeterliliğine sahip olmaları gerekmektedir (Cretu ve Cretu, 2014: 3).

\section{ARAŞTIRMANIN YÖNTEMI}

\subsection{Araştırmanın Amacı, Modeli ve Hipotezler}

$\mathrm{Bu}$ araştırmanın amacl, beşeri sermaye ile eleştirel düşünme eğiliminin arasındaki ilişkinin tespit edilmesidir.

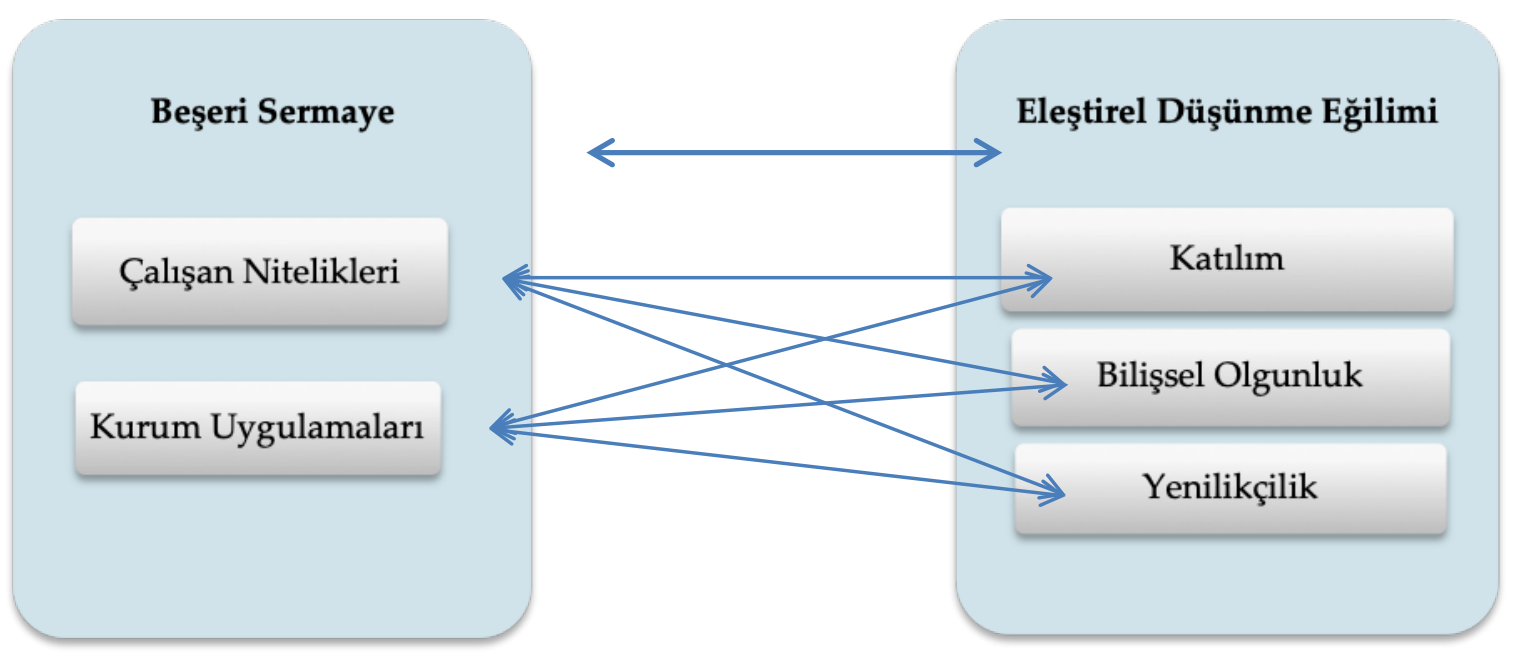

Şekil 1: Araştırmanın Modeli

Araştırmanın amacı doğrultusunda oluşturulmuş olan modele bağlı olarak kurulan hipotezler şunlardır: $\mathrm{H}_{1}$ : Beşeri sermaye ile eleştirel düşünme eğilimi arasında pozitif yönlü doğrusal bir ilişki bulunmaktadır. $\mathrm{H}_{2}$ : Çalışan nitelikleri boyutu ile katılım boyutu arasında pozitif yönlü doğrusal bir ilişki bulunmaktadır. 
H3: Çalışan nitelikleri boyutu ile bilişsel olgunluk boyutu arasında pozitif yönlü doğrusal bir ilişki bulunmaktadır.

$\mathrm{H}_{4}$ : Çalışan nitelikleri boyutu ile yenilikçilik boyutu arasında pozitif yönlü doğrusal bir ilişki bulunmaktadır. $\mathrm{H}_{5}$ : Kurum uygulamaları boyutu ile katılım boyutu arasında pozitif yönlü doğrusal bir ilişki bulunmaktadır.

H6: Kurum uygulamaları boyutu ile bilişsel olgunluk boyutu arasında pozitif yönlü doğrusal bir ilişki bulunmaktadır.

H7: Kurum uygulamaları boyutu ile yenilikçilik boyutu arasında pozitif yönlü doğrusal bir ilişki bulunmaktadır.

\subsection{Araştırmanın Kapsamı, Sınırlılıkları ve Varsayımları}

Araştırma eğitim alanında faaliyet gösteren bir kamu kurumunda yapılmıştır. Zamanın etkin kullanılabilmesi, uygulama yapmanın kolay olması ve maliyet unsurları gibi kısıtlar göz önüne alınarak araştırma Uşak ilinde yapılmıştır. Gerekli izinler ve etik kurul kararı alınmıştır. İlgili kamu kurumunda görev yapan 657 sayılı Devlet Memurları Kanunu'na tabi 300 kamu personeli araştırmanın evrenini oluşturmaktadır. Örneklem seçiminde kolayda örnekleme yöntemi kullanılmış olup, veriler araştırmaya gönüllü olarak katılan 208 kamu personelinden toplanmıştır. Yapılan değerlendirme sonucunda 8 anket formu analizden çıkartılmıştır. Dolayısıyla araştırmada 200 katılımcıdan elde edilen veriler analiz edilmiştir. Bu araştırmada, araştırmaya katılan kamu personelinin ankette yer alan ifadelere yönelik düşüncelerini ve deneyimlerini dürüst bir şekilde aktardıkları varsayılmıştır.

\subsection{Veri Toplama Araçları ve Teknikleri}

Araştırmada nicel araştırma yöntemi kullanılmış olup, veriler anket tekniği ile toplanmıştır. Araştırma verilerini toplamak için kullanılan anket formu, kamu personelinin demografik özelliklerine yönelik soruların yanısıra 5'li Likert tipinde hazırlanmış olan Beşeri Sermaye ölçeği ve UF/UMI Eleştirel Düşünme Eğilimi ölçeğinden oluşmaktadır. Katılımcıların demografik özellikleri olarak cinsiyet, yaş, eğitim durumu, çalışma yılı ve unvanları ele alınmıştır.

Beşeri Sermaye Ölçeği: Vidotto vd. (2019) tarafından geliştirilen beşeri sermaye ölçeği araştırmacılar tarafından Türkçe'ye uyarlanmıştır. Ölçeğin Türkçe'ye uyarlanmış hali "çalışan nitelikleri" 9 ifade ve "kurum uygulamaları" 8 ifade olmak üzere iki boyuttan ve 17 ifadeden oluşmaktadır. Çalışan nitelikleri boyutunda çalışanların liderlik, tutum, deneyim, eğitim, bilgi ve becerileri ile ilgili ifadeler yer almaktadır. Kurum uygulamaları boyutunda ise çalışanların geliştirilmesine, verimliliğinin sağlanmasına, görüş ve önerilerinin alınmasına, çalışanlar arasında işbirliğinin ve bilgi paylaşımının desteklenmesine ve genel memnuniyetin sağlanmasına yönelik uygulamaları içeren ifadeler yer almaktadır.

UF/UMI Eleştirel Düşünme Eğilimi Ölçeği: Florida Üniversitesi araştırmacıları tarafından geliştirilen ölçeğin Türkçe'ye uyarlaması Kılıç Ertaş ve Şen (2014) tarafından yapılmıştır. Ölçeğin Türkçe'ye uyarlanmış hali "katılım" 11 ifade, "bilişsel olgunluk" 7 ifade ve "yenilikçilik" 7 ifade olmak üzere üç alt boyuttan ve 25 ifadeden oluşmaktadır. Katılım boyutu, sorunları çözmek ve karar almak için eleştirel düşünme becerilerini kullanılmasına yönelik öngörülen durumları ifade etmektedir. Katılım boyutunda öneriler getirme, ilgi gösterme, bilgilerini kullanma, sorunları tanımlama ve çözüme, katkı sağlama gibi ifadeler yer almaktadır. Bilişsel olgunluk boyutu, kendi değerlerinin ve önyargıların farkında olmayı ifade etmektedir. Bu boyutta sorunların karmaşıklığının farkında olma, başkalarının görüşlerine açık olma, bir kişinin ve diğerinin yatkınlıklarının ve önyargılarının farkında olma ve karar vermeden önce bu faktörleri objektif olarak değerlendirme eğilimine yönelik ifadeler yer almaktadır. Yenilikçilik boyutu, gerçeği bulmak için entelektüel olarak meraklı olmayı ifade etmektedir. Yenilikçilik boyutunda bilgiye ulaşma, öğrenme ve araştırma yapmaya yönelik ifadeler yer almaktadır.

\subsection{Verilerin Analizleri}

Araştırma verileri SPSS 22 ve Amos 22 programı kullanılarak analiz edilmiştir. Araştırmada kullanılan Beşeri Sermaye Ölçeği ile UF/EMI Eleştirel Düşünme Eğilim Ölçeğinin geçerliliğine yönelik doğrulayıcı faktör analizi yapılmıştır. Ölçeklerin güvenilirliği, Cronbach's Alpha katsayısı ile değerlendirilmiştir. Değişkenler arasındaki ilişkinin tespiti için korelasyon analizi yapılmıştır. 


\section{BULGULAR}

\subsection{Araştırmaya Katılanlarla İlgili Bazı Tanıtıcı Bilgiler}

Araştırmaya katılan kamu personelinin demografik özelliklerine ilişkin tanımlayıcı istatistikler Tablo 1' de verilmiştir.

Tablo 1. Araştırmaya Katılanlarla İlgili Bazı Tanıtıcı Bilgiler

\begin{tabular}{|c|c|c|c|c|c|}
\hline Değişken & Frekans & $\%$ & Değişken & Frekans & $\%$ \\
\hline \multicolumn{3}{|l|}{ Cinsiyet } & \multicolumn{3}{|l|}{ Yaş } \\
\hline Kadın & 73 & 36,5 & 29 ve altı & 26 & 13,0 \\
\hline Erkek & 127 & 63,5 & $30-34$ & 58 & 29,0 \\
\hline \multicolumn{3}{|l|}{ Ĕgitim } & 35-39 & 42 & 21,0 \\
\hline Lise & 21 & 10,5 & $40-44$ & 31 & 15,5 \\
\hline Önlisans & 24 & 12,0 & 45 ve üstü & 43 & 21,5 \\
\hline Lisans & 135 & 67,5 & \multicolumn{3}{|l|}{ Çalışma Yılı } \\
\hline Lisansüstü & 20 & 10,0 & $1-5$ & 28 & 14,0 \\
\hline \multicolumn{3}{|l|}{ Unvan } & $6-10$ & 66 & 33,0 \\
\hline Memur & 151 & 75,5 & $11-15$ & 40 & 20,0 \\
\hline Yönetici & 31 & 15,5 & $16-20$ & 19 & 9,5 \\
\hline Teknik Personel & 18 & 9,0 & 21 ve üzeri & 47 & 23,5 \\
\hline
\end{tabular}

\subsection{Faktör Analizi ve Güvenilirlik Analizi}

Beşeri Sermaye ve UF/EMI Eleştirel Düşünme Eğilimi ölçeklerinin bu araştırmada geçerliliğini belirlemek için Amos 22 programı aracılığıyla doğrulayıcı faktör analizi (DFA) yapılmıştır. Ölçeklerin bu araştırmada güvenilirliğini belirlemek için Cronbach's Alpha Katsayısı kullanılmıştır.

Beşeri sermaye ölçeğine yönelik yapılan DFA sonucunda bir ifade (Personelin deneyimi kurumsal faaliyetlerin gelişimi için kilit bir unsurdur) analizden çıkartılmıştır. Modifikasyon önerileri doğrultusunda aynı örtük değişkene ait hata terimleri arasında (çalışan nitelikleri değişkeninin e7-e8 hata terimleri ile kurum uygulamaları değişkeninin e10-e12 ve e13-e15 hata terimleri arasında) kovaryans atanmıştır. Yapılan doğrulayıc faktör analizi sonucunda beşeri sermaye ölçeğinin test değerleri $x^{2}(144,929), \mathrm{df}(112), x^{2} / \mathrm{df}$ $(1,294)$ istatistiksel olarak anlamlı ve uyum indeks değerleri GFI $(, 924)$, NFI $(, 903)$, CFI $(, 976)$, RMSEA $(, 038)$ ve SRMR (,0536) kabul edilebilir sınırlar içinde olduğu görülmektedir (Schermelleh-Engel vd., 2003: 52). Bu sonuçlarla birlikte beşeri sermaye ölçeğinin kullanılabilir olduğu anlaşılmıştır (Tablo 2).

Tablo 2. Beşeri Sermaye Ölçeğinin DFA Sonuçları

\begin{tabular}{cccccccccc}
\hline Ölçek & $\mathbf{x}^{\mathbf{2}}$ & $\mathbf{d f}$ & $\mathbf{x}^{2} / \mathbf{d f}$ & GFI & NFI & CFI & RMSEA & SRMR & $\begin{array}{c}\text { Cronbach's } \\
\text { Alpha }\end{array}$ \\
\hline $\begin{array}{c}\text { Beşeri } \\
\text { Sermaye }\end{array}$ & 144,929 & 112 & 1,294 &, 924 &, 903 &, 976 &, 038 &, 0536 &, 897 \\
\hline
\end{tabular}

Beşeri sermaye ölçeği için yapılan güvenirlik analizi sonucunda Cronbach's Alpha katsayıları "çalışan nitelikleri" boyutunun $\alpha=0,867$, “kurum uygulamaları" boyutunun $\alpha=0,846$ ve ölçeğin genel $\alpha=0,897$ 'dir. $\mathrm{Bu}$ sonuçlara göre beşeri sermaye ölçeğinin ve alt boyutlarının güvenilirlik seviyesinin yüksek olduğu tespit edilmiştir (Kayış 2016: 405).

UF/EMI eleştirel düşünme eğilimi ölçeğine yönelik yapılan DFA sonucunda modifikasyon önerileri doğrultusunda sırasıyla 5., 6., 1., 4., 15., 7., 8. ve 22. maddeler ölçekten çıartılmıştır. UF/EMI eleştirel düşünme eğilimi ölçeğinin test değerleri $x^{2}(206,843)$, df $(108), x^{2} / d f(1,915)$ istatistiksel olarak anlamlı ve uyum indeks değerleri GFI (,900), NFI (,905), CFI (,951), RMSEA $(, 068)$ ve SRMR $(, 0450)$ kabul edilebilir sınırlar içinde olduğu görülmektedir (Schermelleh-Engel vd., 2003: 52). Bu sonuçlarla birlikte UF/EMI ölçeğinin kullanılabilir olduğu anlaşılmıştır (Tablo 3). 
Tablo 3. UF/EMI Eleştirel Düşünme Eğilimi Ölçeğinin DFA Sonuçları

\begin{tabular}{cccccccccc}
\hline Ölçek & $\mathbf{x}^{2}$ & $\mathbf{d f}$ & $\mathbf{x}^{2} / \mathbf{d f}$ & GFI & NFI & CFI & RMSEA & SRMR & $\begin{array}{c}\text { Cronbach's } \\
\text { Alpha }\end{array}$ \\
\hline UF/EMI & 206,843 & 108 & 1,915 &, 900 &, 905 &, 951 &, 068 &, 0450 &, 940 \\
\hline
\end{tabular}

UF/EMI ölçeği için yapılan güvenilirlik analizi sonucunda Cronbach's Alpha katsayıları "katılım" boyutunun $\alpha=, 909$, "bilişsel olgunluk" boyutunun $\alpha=, 811$, "yenilikçilik" boyutunun $\alpha=, 784$ ve UF/EMI ölçeğinin $\alpha=, 940$ 'dır. UF/EMI ölçeğinin ve alt boyutlarının güvenilirlik seviyesinin yüksek olduğu belirlenmiştir (Kayış 2016: 405).

\subsection{Korelasyon Analizi}

Beşeri sermaye ve alt boyutları ile eleştirel düşünme eğilimi ve alt boyutları arasındaki ilişkinin yönü ve gücünü tespit etmek üzere korelasyon analizi yapılmıştır. Korelasyon analizinin sonucuna göre; beşeri sermaye ve alt boyutları ile eleştirel düşünme ve alt boyutları arasında pozitif yönde anlamlı ilişkiler tespit edilmiştir (Tablo 4).

Tablo 4. Beşeri Sermaye ve Eleştirel Düşünme Eğilimi Korelasyon Analizi

\begin{tabular}{|c|l|c|c|c|c|c|c|c|c|c|}
\hline & \multicolumn{1}{|c|}{ Değişkenler } & Ort. & SS & 1 & 2 & 3 & 4 & 5 & 6 & 7 \\
\hline 1 & Beşeri Sermaye & 2,80 &, 736 & 1 & & & & & & \\
\hline 2 & Çalışan Nitelikleri & 3,06 &, 805 &, $893^{* *}$ & 1 & & & & & \\
\hline 3 & Kurum Uygulamaları & 2,73 &, 652 &, $860^{* *}$ &, $581^{* *}$ & 1 & & & & \\
\hline 4 & Eleştirel Düşünme Eğilimi & 4,14 &, 700 &, $204^{* *}$ &, $232^{* *}$ &, $149^{*}$ & 1 & & & \\
\hline 5 & Katılım & 2,51 &, 858 &, $880^{* *}$ &, $571^{* *}$ &, $954^{* *}$ &, 127 & 1 & & \\
\hline 6 & Bilişsel Olgunluk & 4,03 &, 757 &, 127 &, $153^{*}$ &, 101 &, $892^{* *}$ &, $071^{* *}$ & 1 & \\
\hline 7 & Yenilikçilik & 4,22 &, 794 &, $206^{* *}$ &, $223^{* *}$ &, $165^{*}$ &, $919^{* *}$ &, $140^{*}$ &, $767^{* *}$ & 1 \\
\hline
\end{tabular}

${ }^{* *} \mathrm{p}<0,01,{ }^{*} \mathrm{p}<0,05$

Araştırmaya katılan kamu personelinin kurumun beşeri sermayesine yönelik algılarının düşük olduğu tespit edilmiştir. Ayrıca beşeri sermayeyi geliştirmeye yönelik kurumsal uygulamalar yeterli düzeyde değildir. Bu durum eleştirel düşünme eğiliminin katılım boyutunda da görülmektedir. Kamu personelinin verilen kamu hizmetinin geliştirilmesine yönelik görüş ve önerilerini dile getirebileceği uygun ortamın olmadığı görülmektedir.

Beşeri sermaye ile eleştirel düşünme eğilimi arasında $(r=.204, p<0.01)$ pozitif yönde anlamlı ilişki bulunmaktadır. Dolayısıyla $\mathrm{H}_{1}$, hipotezi kabul edilmiştir. Beşeri sermaye ile eleştirel düşünme eğilimi değişkeninin alt boyutları arasında katılım $(r=.880, p<0.01)$ ve yenilikçilik $(r=.206, p<0.01)$ pozitif yönde anlamlı ilişki olduğu tespit edilmiştir. Ancak beşeri sermaye ile bilişsel olgunluk boyutu arasında $(r=.127$, p >0.05) anlamlı bir ilişki bulunmamaktadır.

Çalışan nitelikleri boyutu ile eleştirel düşünme eğilimi değişkeninin alt boyutları arasında katılım $(\mathrm{r}=.571$, $\mathrm{p}<0.01)$, bilişsel olgunluk $(\mathrm{r}=.153, \mathrm{p}<0.05)$ ve yenilikçilik $(\mathrm{r}=.223, \mathrm{p}<0.01)$ pozitif yönde anlamlı ilişki olduğu tespit edilmiştir. Dolayısıyla $\mathrm{H}_{2}, \mathrm{H}_{3}$ ve $\mathrm{H}_{4}$ hipotezleri kabul edilmiştir.

Kurum uygulamaları boyutu ile eleştirel düşünme eğilimi değişkeninin alt boyutları arasında katılım $(r=$ .954, $\mathrm{p}<0.01)$ ve yenilikçilik $(\mathrm{r}=.165, \mathrm{p}<0.01)$ pozitif yönde anlamlı ilişki olduğu tespit edilmiştir. Ancak beşeri sermaye ile bilişsel olgunluk boyutu arasında $(\mathrm{r}=.101, \mathrm{p}>0.05)$ anlamlı bir ilişki bulunmamaktadır. Dolayısıyla $\mathrm{H}_{5}$ ve $\mathrm{H}_{7}$ hipotezleri kabul edilmiş, $\mathrm{H}_{6}$ hipotezi ise reddedilmiştir.

\section{TARTIŞMA VE SONUÇ}

$\mathrm{Bu}$ araştırmada beşeri sermaye ile eleştirel düşünme eğilim arasındaki ilişki incelenmiş ve Uşak ilinde eğitim alanında faaliyet gösteren bir kamu kurumunda anket uygulaması yapılmıştır. Elde edilen veriler doğrultusunda uygulanan korelasyon analizi sonucunda beşeri sermaye ile eleştirel düşünme arasında pozitif doğrusal bir ilişki bulunduğu tespit edilmiştir. Bilginin her türlü üretimin temel kaynağı haline 
gelmesiyle birlikte, bu bilginin işlenmesi ve ürün veya hizmete dönüştürülmesi becerili ve yetenekli bireyleri gerektirmektedir. Beşeri sermaye yenilik, refah, zenginlik, gelişme, sürdürülebilir rekabet avantajı gibi unsurların temel kaynağıdır. Bu nedenle beşeri sermayenin niteliği hem ülkeler hem de örgütler açısından önem kazanmıştır. Kaliteli beşeri sermayeye sahip olmak özel sektör kuruluşları kadar, kamu sektörü içinde artık bir zorunluluk haline gelmiştir. Dolayısıyla araştırma sonucunda kamu kurumlarında beşeri sermayenin geliştirilmesi noktasında kullanılabilecek araçlardan birisinin de eleştirel düşünme olduğu ortaya konulmuştur.

Değişkenlerin alt boyutlarına ilişkin sonuçlarda kamu yönetiminde beşeri sermaye ve eleştirel düşünmenin önemini vurgulamaktatır. Elde edilen bulgulara göre en yüksek ilişki beşeri sermaye ve alt boyutları ile eleştirel düşünme eğiliminin katılım boyutu arasında ortaya çıkmıştır. Sayıları dört milyonu aşan kamu personelinin sadece verilen emir ve görevleri yerine getirmesi çağdaş kamu yönetimi anlayışında yeterli görülmemektedir. Bu nedenle klasik yönetim anlayışı ve kamu personelinin emir odaklı çalışma yapısının değişmesi gerekmektedir. Vatandaşlar ile doğrudan iletişim ve etkileşim halinde bulunan, kamu hizmeti sürecinde oluşan aksaklıkları ve sorunları bire bir deneyimleyen kamu personelinin karar alma süreçlerine daha etkin bir şekilde katılması sağlanmalıdır. Eleştirel düşünmenin en önemli bileşeni olan katılım boyutu kamu yönetiminde daha katılımcı ve demokratik yönetim anlayışının gelişmesine katkı sağlayacaktır.

Çalışan nitelikleri boyutu ile bilişsel olgunluk boyutu arasında da pozitif yönlü anlamlı bir ilişki mevcuttur. Ülkemizde kamu kurumları çalışanlarını merkezi sınav vasıtasıyla seçmekte ve istihdam etmektedir. Dolayısıyla kamu kurumlarının çalıştıracakları personelin niteliklerini belirlemede sınırlı söz hakkı bulunmaktadır. Ancak görev yapan kamu personelinin hizmet içi eğitimlerle niteliklerinin geliştirilmesi kamu kurumlarının takdirindedir. Fakat bu tek taraflı bir süreç değildir. Kamu personelinin de bu sürece katılım sağlamaya gönüllü, bilişsel olgunluğa sahip ve yeniklere açık olmaları gerekmektedir.

Kurum uygulamaları ve çalışan nitelikleri boyutları ile yenilikçilik boyutu arasında da pozitif yönlü anlamlı bir ilişki bulunmaktadır. Kamu personelinin hizmet sürecini geliştirmeye yönelik önerileri, bu önerilerin dikkate alınacağı ve etkili katılımın sağlanacağı bir ortamın oluşturulması kamu kurumları için zorunlu hale gelmiştir. Kamu yöneticileri kişisel çıarlarını ve siyasal kaygılarını bir kenara bırakıp daha iyi hizmet üretmenin yollarını araştırmalı ve çalışanlarından gelen önerileri dikkate almalıdır. Dolayısıyla kamu kurumları beşeri sermayelerini geliştirmeye yönelik yatırımlar yapmak zorundadır.

Kamu kurumları, vatandaşlardan toplanan vergilerle finanse edilmekte ve bu sinırlı kaynağı kullanmaktadır. Bu kurumların maddi kaynaklarını etkili, ekonomik ve verimli kullanılması yasal bir zorunluluktur. Ayrıca kamu kurumları görevlerini hesap verilebilirlik çerçevesinde, şeffaf bir şekilde yerine getirmelidir. Maddi kaynakların etkin kullanılmamasının ortaya çıkardığı sorunların yanısıra, kamu kurumlarının en önemli maddi olmayan varlıkları olan beşeri sermayelerinden etkili ve verimli bir şekilde yararlanılamaması daha büyük sorunlara yol açmaktadır.

Beşeri sermaye ile eleştirel düşünme eğilimi arasındaki pozitif doğrusal ilişki kamu kurumları tarafından dikkate alınırsa, kamu hizmetinin iyileştirilmesi, etkinlik ve verimliliğin artırılması, çalışan motivasyonunu ve doyumunun sağlanması, inovasyonun gerçekleştirilmesi gibi önemli alanlarda kazanımlar elde edilecektir. Ayrıca katılımcı liderlik anlayışı ve işbirliği ve bilgi paylaşımına dayalı bir örgüt kültürünün oluşmasına da katkı sağlayacaktır.

$\mathrm{Bu}$ araştırma Uşak ilinde eğitim alanında faaliyet gösteren bir kamu kurumunda gerçekleştirilmiştir. Araştırmanın tüm kamu yönetimini temsil edebilecek bir örneklemde yapılması genellenebilirlik açısından anlamlı olabilir. Bunun yanısıra beşeri sermayenin geliştirilmesi ve eleştirel düşünme eğiliminin artırılmasında liderlik ve örgüt kültürünün etkisinin araştırılması önerilmektedir.

\section{Kaynakça}

Agndal, H. ve Nilsson, U. (2006). Generation of Human and Structural Capital: Lessons from Knowledge Management. The Electronic Journal of Knowledge Management, 4(2), 91-98.

Akyüz, Ö. F. (2011). İnsan ve Bilgi Ekseninde Entelektüel Sermayenin Etkin Yönetimi. İstanbul: THY Teknik A.Ş.

Alston, K. (2001). Re/Thinking Critical Thinking: The Seductions of Everyday Life. Studies in Philosophy and Education, (20), 27-40. 
Arıkboğa, Ş. (2003). Entellektüel Sermaye. İstanbul : Derin Yayınları.

Bassi, L. J. ve Van Buren, M. E. (1999). Valuing investments in intellectual capital. International Journal of Technology Management, 18(5), 414-433.

Becker, G. S. (1993). Human Capital A Theoretical and Empirical Analysis with Special Reference to Education. Chicago : The University of Chicago Press.

Bontis, N. (1998). Intellectual Capital: An Exploratory Study That Develops Measures and Models. Management Decision, 36(2), 63-76.

Bounfour, A. ve Edvinsson, L. (2005). Introduction. A. Bounfour ve L. Edvinsson (Ed.) içinde, Intellectual Capital for Communities (s. xi-xv). Massachusetts: Elsevier Butterworth-Heinemann.

Brooking, A. (1996). Intellectual Capital. London: International Thomson Business Press.

Campos, E. B., Salmador, M. P. ve Merino, C. (2006). Towards A Model of Intellectual Capital in Public Administrations. Learning and Intellectual Capital, 3(3), 214-232.

Carkhuff, R. R. (2000). Human Possibilities Human Capital in the 21. Century. Massachusetts: Possibilities Publishing.

Castells, M. (2013). Enformasyon Çă̆g: Ekonomi, Toplum ve Kültür, I. Cilt. (E. Kılıç, Çev.) İstanbul: İstanbul Bilgi Üniversitesi Yayınları.

Cinca, C. S., Molinero, C. M., \& Queiroz, A. B. (2003). The Measurement of Intangible Assets in Public Sector Using Scaling Techniques. Journal of Intellectual Capital, 4(2), 249-275.

Cretu, V. ve Cretu, N. (2014). Critical Thinking Competency for an Open Government. Topic Report No. 2014/11: European Public Sector Information Platform.

Daniello, R. J. ve Laubsch, P. (2008). Scenarios in Public Administration: Critical Thinking Exercises. Maryland: University Press of America.

Davenport, T. H. (2006). Düşünerek Yaşayanlar. (V. Karatay, Çev.) İstanbul: Bahçeşehir Üniversitesi Yayınları.

Drucker, P. (2017). İnovasyon ve Girişimcilik: Uygulama ve İlkeler. (İ. Gülfidan, Çev.) İstanbul: Optimist Yayıncilik.

Edvinsson, L. (1997). Developing Intellectual Capital at Skandia. Long Range Planning, 30(3), 366-373.

Ennis, R. H. (2018). Critical Thinking Across the Curriculum: A Vision. Topoi, (37), 165-184.

Facione, P. A. (1990). Critical Thinking: A Statement of Expert Consensus for Purposes of Educational Assessment and Instruction Research Findings andRecommendations. Newark, Del.: American Philosophical Association.

Farah, A. ve Abouzeid, S. (2017). The impact of intellectual capital on performance: Evidence from the public sector. Knowledge Management \& E-Learning, 9(2), 225-238.

Guitton, J. (2011). Düşünme Sanatı. (C. Perin, Çev.) Ankara: Elips Kitap.

Johnson, R. H. ve Hamby, B. (2015). A Meta-Level Approach to the Problem of Defining 'Critical Thinking'. Argumentation, (29), 417-430.

Kayış, A. (2016). Güvenilirlik Analizi. Ş. Kalaycı (Ed.) içinde, SPSS Uygulamalı Çok Değişkenli İstatistik Teknikleri. 7. Baskı (s. 403-419). Ankara: Asil Yayın Dağıtım.

Kılıç Ertaş, H. ve Şen, A. İ. (2014). UF/EMI Eleştirel Düşünme Eğilimi Ölçeğini Türkçeye Uyarlama Çalışması. Ĕ̆itim ve Bilim, 39(176), 1-12.

Lipman, M. (1988). Critical thinking: What can it be? Educational Leadership, (46), 38-43.

Martincova, J. ve Lukesova, M. (2015). Critical Thinking as a Tool for Managing Intercultural Conflicts. Procedia - Social and Behavioral Sciences, (171), 1255-1264. 
Ş. Erten - İ. Türkmen 12/1 (2020) 321-331

Matovac, V. A., Bilas, V. ve Franc, S. (2010). Understanding the Importance of Human Capital and Labor Market Competitiveness in the EU Candidate Countries and Selected EU Memebers. Economic Thought and Practice, (2), 359-382.

Microsoft. (2014). Developing Critical Thinking Through Web Research Skills. http://download.microsoft.com/download/A/6/4/A645E848-4937-4564-9CF616A57EF8BF48/CriticalThinking.pdf (Erişim Tarihi: 12.10.2019).

OECD. (1999). Programme Notes and Background. An International Symposium Measuring and Reporting Intellectual Capital: Experience, Issues, and Prospects. Amsterdam: OECD.

Oliver, R. W. (2001). The Return on Human Capital. Journal Of Business Strategy, July/August, 7-10.

Özkan, H. H. (2009). Bilgi Toplumu Eğitim Programları. SDÜ sosyal Bilimler Enstitüsü Dergisi, 2(10), 113-132.

Özsağır, A. (2016). Bilgi Ekonomisi: Tanım, Uygulamalar, Örnekler. Ankara: Seçkin Yayıncllık.

Paul, R. ve Elder, L. (2016). Kritik Düşünce. (E. Aslan ve G. Sart, Çev.) Ankara: Nobel Yayıncılık.

Petty, R. ve Guthrie, J. (2000). Intellectual capital literature review: Measurement, Reporting and Management. Journal of Intellectual Capital, 1(2), 155-176.

Possin, K. (2014). Critique of the Watson-Glaser Critical Thinking Appraisal Test: The More You Know, the Lower Your Score. Informal, 34(4), 393-416.

Roos, C. (2008). The Use of Human Capital for Good Governance. Institute of Social Studies.

Ruggiero, V. R. (2017). Eleştirel Düşünme İçin Bir Rehber. (Ç. Dedeoğlu, Çev.) İstanbul: Alfa Yayıncılık.

Sarnovics, A. (2010). Human Resource Development in Public Administration: A Case of Latvia. Human Resources Management \& Ergonomics, 4(1), 1-12.

Schermelleh-Engel K., Moosbrugger H. and Müller H. (2003). Evaluating the Fit of Structural Equation Models: Tests of Significance and Descriptive Goodness-of-Fit Measures. Methods of Psychological Research Online, 8(2), 23-74.

Schultz, T. W. (1993). The Economic Importance of Human Capital in Modernization. Education Economics, $1(1), 13-19$.

Scriven, M. ve Paul, R. (1987). Presentation. 8th Annual International Conference on Critical Thinking and Education Reform. http://www.criticalthinking.org/pages/defining-critical-thinking/766 (Erişim Tarihi: 10.11.2019).

Segler, H. (2015). Critical Thinking: Powerful Strategies That Will Make You Improve Decisions And Think Smarter. CreateSpace Independent Publishing Platform.

Stewart, T. A. (1997). Entellektüel Sermaye: Örgütlerin Yeni Zenginliği. İstanbul: MESS Yayınları.

Tarchi, C. ve Mason, L. (2019). Effects of Critical Thinking on Multiple-Document Comprehension. European Journal of Psychology of Education,1-25, https://doi.org/10.1007/s10212-019-00426-8.

Trevors, J. T. (2011). Critical Thinking: Apply It to Global Pollution! Water Air Soil Pollut, (218), 1-2.

Vidotto, J. D., Ferenhof, H. A., Selig, P. M. ve Bastos, R. C. (2017). A Human Capital Measurement Scale. Journal of Intellectual Capital, 18(2), 316-329.

Weatherly, L. A. (2003). Human Capital-The Elusive Asset. Virginia: Society for Human Resource Management.

Weissberg, R. (2013). Critically Thinking about Critical Thinking. Academic Questions, 26(3), 317-328.

Yeh-Yun Lin, C. ve Edvinsson, L. (2011). National Intellectual Capital. London: Springer.

Zulmaulida, R., Wahyudin ve Dahlan, J. A. (2018). Watson-Glaser's Critical Thinking Skills. Journal of Physics: Conference Series: 1028. 